Article

\title{
Sustainable Construction Supply Chains through Synchronized Production Planning and Control in Engineer-to-Order Enterprises
}

\author{
Patrick Dallasega * (D) and Erwin Rauch \\ Faculty of Science and Technology, Free University of Bozen-Bolzano, Universitätsplatz 5, 39100 Bolzano, Italy; \\ erwin.rauch@unibz.it \\ * Correspondence: patrick.dallasega@unibz.it; Tel.: +39-0471-017114
}

Received: 8 September 2017; Accepted: 18 October 2017; Published: 20 October 2017

\begin{abstract}
Sustainability in the supply chain is becoming more and more important for industrial enterprises in different sectors. This research article focuses on construction supply chains (CSCs) in the Engineer-to-Order (ETO) industry, where every product is almost unique based on specific customer needs and requirements. The development of methods and approaches for more sustainable supply chain management in construction is becoming even more important. Engineering, fabrication of parts and their installation on-site are not always well synchronized in ETO supply chains. The results of such supply chains are long lead times, inefficient material transport and high and uncontrolled levels of work-in-progress (WIP). This article describes a conceptual approach to synchronize demand on-site with supply in manufacturing using the CONstant Work In Progress (ConWIP) concept from Lean Management to achieve Just-in-Time (JIT) supply. As a result, sustainable supply chains in ETO enterprises, with optimizations from an economic, ecological and social point of view, can be designed. The approach has been validated in an industrial case study.
\end{abstract}

Keywords: construction; supply chain management; engineer-to-order; sustainability; resource efficiency; just-in-time; constant work in progress

\section{Introduction}

A growing number of enterprises are working on the implementation of sustainable manufacturing and supply chain processes. The objective of sustainable supply chain initiatives is the creation of products or objects by means of energy-efficient, resource-saving as well as socially acceptable processes [1]. Customer satisfaction will be achieved in future not only through the creation of the product itself, but also through socially and environmentally responsible as well as economically efficient concepts of manufacturing avoiding negative effects for society [2]. Thus, we need modern organizational models and approaches to design supply chains with a focus on sustainability. In this paper, there is special emphasis on the ETO construction industry focusing on a case study from façade manufacturing industry. Construction supplier companies can be classified according to different market interaction strategies (Figure 1): (1) Make-to-Stock (MTS); (2) Assemble-to-Order (ATO); (3) Production-on-Demand (POD); (4) Build-to-Order (BTO); (5) Configure-to-Order (CTO) and (6) Engineer-to-Order (ETO) [3,4]. 


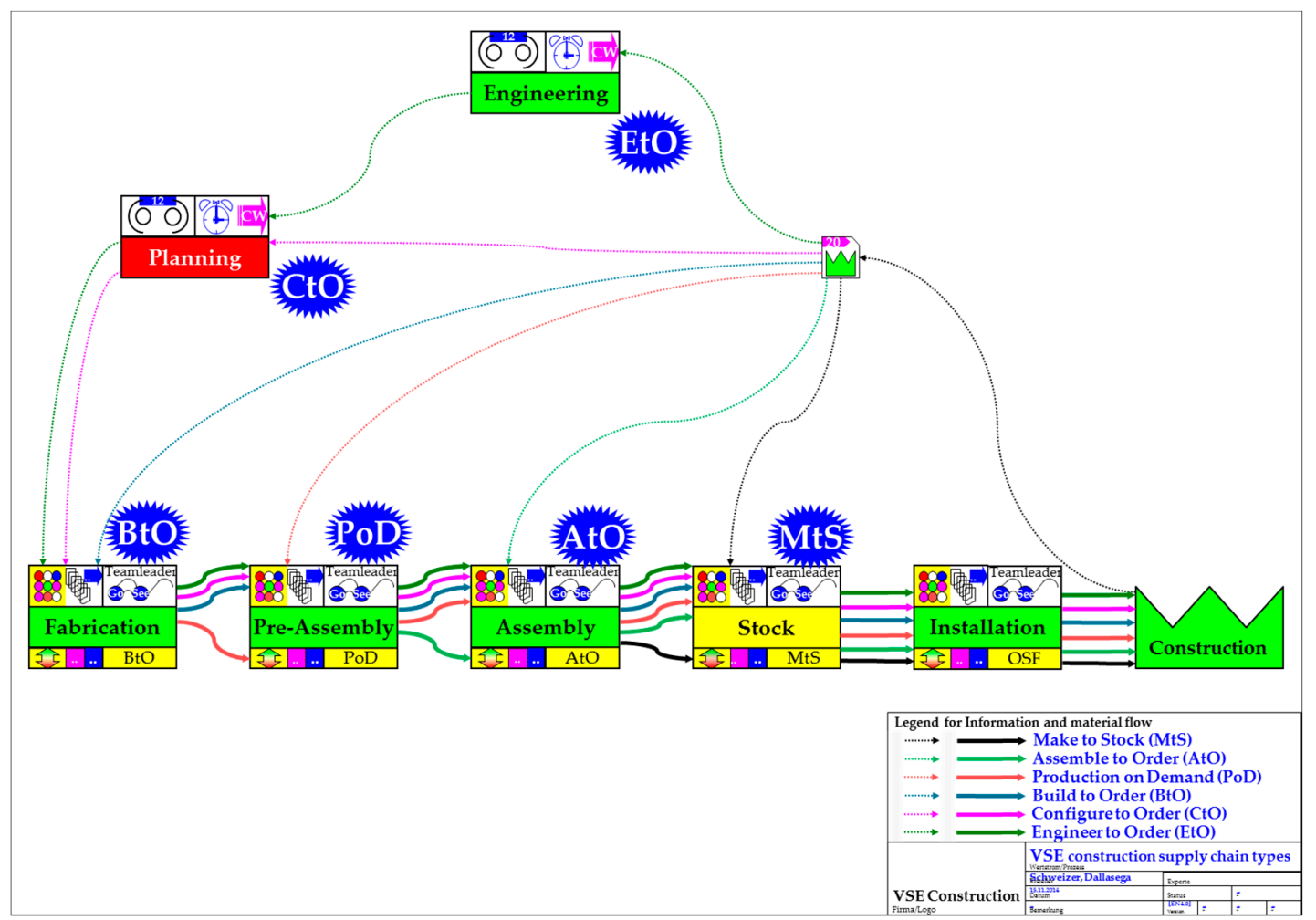

Figure 1. Market interaction strategies for construction suppliers [5].

As in many ETO construction supply chains (CSCs), the problem of traditional façade producers is that manufacturing processes are disconnected from the installation on-site [6]. This is emphasized by considering tier one suppliers, which produce and deliver their products from a fabrication shop to the construction site for installation. As a consequence, economic benefits reached through scale effects in production, are often lost due to an inefficient installation process on-site [7]. ETO companies are characterized by products or singular components that are engineered (developed) and produced according to a specific customer order. This means that every product is unique and therefore different from the other and standardization in production or installation is almost impossible [8]. This customization of products also makes it difficult to gain from learning curves during development, fabrication and installation on-site. Another challenge in the construction industry is the efficient usage of human resources on different projects. Very often ETO enterprises have to manage several projects in different places or countries through accurate multi-project management [9]. Switching personnel frequently between different projects to meet critical deadlines is not recommended, because this means there is an initial learning effort and thus inefficiencies in resource use.

Typical first-tier ETO supply chains in the construction industry consider three different macro-phases [6]:

1. Engineering

2. Fabrication

3. Installation on-site

Traditionally, ETO-projects are not synchronized to the three phases and, therefore, budget overruns occur. The causes for this are manifold. An example could be if fabrication is not informed about the progress of installation on-site. In this case, the fabrication shop could produce too much (overproduction) generating a lot of stock at the production site or at the construction site. In another scenario, faster progress on-site could lead to a bottleneck in material supply, if production is not informed regularly about the construction progress. The same lack of integration and information also 
occurs between engineering and manufacturing. Installation and/or manufacturing are not able to go on with their work because of missing information or drawings from engineering. ETO companies design and build products to customer specifications. Thus, a significant amount of time and cost goes into the engineering and design stage of the project. On the other side, if changes occur on the shop floor or on the installation site, project planning and scheduling as well as engineering are not always updated automatically. Additional problems occur due to constant changes in the project by manufacturing, installation or customers themselves [10]. In the fabrication shop, often changes in time schedules are due to technical or logistical problems in order processing. Mostly, the customer requires changes before and during the production or installation of components. This leads to capacity bottlenecks and complexity in project management and in supply chain management. All these changes in engineering, manufacturing and installation have to be synchronized and coordinated.

In Lean Management, inventories or buffers stand for waste (muda) and thus they are handled as activities which are not value-adding. For the purposes of a lean process along the entire value chain from engineering to manufacturing to installation, inventory should be reduced to a minimum. Thus, there is a need to close this gap of synchronization between engineering, manufacturing and on-site installation enabling efficient and sustainable supply chain management with low inventory and a Just-in-Time (JIT) delivery of material and information [6].

The paper is structured as follows: after a short introduction in Section 1, Section 2 describes the theoretical background with a review of sustainability challenges in CSC management and as a response recent works in the field of Lean Management, especially models for JIT-oriented production planning and control. Section 3 deals with the analysis of the actual situation of production planning in typical ETO construction suppliers. Section 4 explains the proposed approach for synchronization from manufacturing to on-site installation in ETO supply chains and in Section 5 the practical application and validation in an industrial case study is presented. Finally, Section 6 discusses the benefits and advantages of the proposed approach to increase sustainability in ETO supply chains based on the three key elements: economic, ecological and social sustainability.

\section{Theoretical Background}

In this section, first sustainability challenges in CSCs are described. As a response, approaches from Lean Management, especially JIT-based models and concepts for production planning and control in construction and especially in the ETO environment are presented.

\subsection{Sustainability in CSCS}

Usually, CSCs are MTO supply chains, which converge all materials to the site where the building is assembled from incoming materials [11-14]. Moreover, especially in the field of individual construction where ETO products are common, CSCs can usually be considered as temporary initiatives characterized by fragmentation, instability and high inefficiency [11,14]. Therefore, SCM concepts developed and applied in other industries, like the manufacturing industry, cannot be directly applied to the construction industry [15]. As a response, Vrijhoef and Koskela presented four specific roles of SCM in construction focusing on the supply chain, the construction site, or both [14]. Here, by means of the design of new supply chain configurations, the aim is to reach a global reduction of transportation, inventory and production costs. Moreover, by means of industrialization and especially prefabrication, moving activities from an uncontrollable environment (the construction site) to a controllable environment (the fabrication shop), the aim is to achieve improvements in terms of quality, time and cost. Unlike the BTO and MTS manufacturing supply chains (see Figure 1) that have successfully developed lean and sustainable supply chain management [16-20], the ETO CSC is yet to realize sustainability due to many complications from the design, fabrication to installation varying in many supply chain partners. In best practice, sustainability of the supply chain is partially realized. Sustainable construction becomes a concern for many companies in the construction industry [16-20]. There exist guidelines for designing sustainable buildings; however, there are different interests and 
focuses between Europe, Asia and America, e.g., construction impact, material usage, procurement and transportation [21,22]. Davies and Davies [23] describe drivers and barriers of sustainability in construction. According to their study, typical drivers are client awareness, regulations, financial incentives or tax burdens while typical barriers are affordability, lack of client awareness as well as a lack of proven alternative technologies.

Many sustainability-related concerns are addressed in research but usually in specific activities, e.g., waste management, designing or purchasing [24-26]. Information Lifecycle Management (ILM) and Information Technology (IT) have been widely used to improve information sharing of ETO. However, these technologies are limited to a specific phase of the CSC [27-30]. Total supply chain information sharing and decision support tools are rather ineffective and inefficient. This results in long lead times and overall supply chain inefficiency [31,32]. A study at Kota Kinabalu by Ali et al. found that environmental and sustainability concerns will not be understood if there is lack of knowledge, tools and skills to address the various issues to support a sustainable development plan [33]. The obstacle for sustainable ETO might focus on the social aspects relating to teach sustainability in education and skilled workers to carry out the work. On the other hand, in small construction environments, the decision-making is rather focused on financial and economic perspectives. Supply chain, human resources, environment and risk management are among recent interests. However, the sustainability aspect is yet to be realized [34-36].

In addition to these specific difficulties, there are some general challenges in the ETO industry. In traditional ETO manufacturing, building components are produced mainly according to the push principle. This means, that shop floor drawings are pushed from engineering to fabrication. In the fabrication shop, components are produced according to the available shop floor drawings. Finally, components are pushed from fabrication to the site for installation. Five of the seven types of waste (identified by Taiichi Ohno [37]) are described as problems, which endanger the sustainability of ETO construction suppliers: overproduction, waiting time, motion, inventory and failure correction [38]. Overproduction means that an upstream process, like engineering or fabrication, produces outputs (like drawings or components) in too large a quantity and before they are actually needed by downstream processes. According to practitioners, the justification for large batch sizes is that "this is how we have always done it" or that some of the machines need long setup times. Moreover, materials are ordered from outstanding suppliers more and sooner than needed to make sure they are available when needed. As a result, overproduction is seen as one of the major types of waste because it triggers the other ones mentioned previously. Often, the cause of missing components on-site (creating construction interruptions and so waiting times) is that the fabrication department cannot produce them, due to the missing information about the progress on-site. In addition, the correction of failures shows an economic as well as ecological waste. Errors in the engineering department or manufacturing are usually only discovered on-site. In this case, the defective components have to be engineered and fabricated again and finally reinstalled; eventually, the old parts have to be scrapped as well. Using big batch sizes, in particular, creates cost explosions if correction operations are necessary. The main cause of big levels of inventory and high expenditure for handling and motion operations at the fabrication shop or at the installation site is the aforementioned lack of synchronization between fabrication and installation. The communication and synchronization between the different departments becomes increasingly complex if installation is geographically far away from the fabrication shop, if the company is working in parallel on many different projects (multi-project management) and if the project is extraordinarily extensive and lengthy. 


\subsection{Review of JIT-Based, Lean Production Planning and Control in ETO CSCS}

In recent decades, Lean Principles have been used in manufacturing and later in construction (Lean Construction) to optimize production flows and to reduce waste. However, according to a study performed by Bevilacqua et al. 2017 [39] a wide application of lean principles can be recognized in larger Italian companies. Smaller enterprises often fear that the implementation of lean concepts is costly and time consuming and that it does not contribute to the business growth of a company. Moreover, smaller firms tend to be more agile and flexible to adjusting themselves to changing market conditions and therefore accepting high production costs [39]. This could be especially considered the case for Italian ETO companies working in the CSC industry.

In contrast to traditional push-oriented production planning and control methods, the theory of Lean Construction suggests the adoption of pull-based models [40]. Push systems are those in which production jobs are scheduled, whereas pull systems are those in which the start of one job is triggered by the completion of another. In push systems, an error in demand forecast causes bullwhip effects. However, in JIT ordering systems, amplifications are avoided because the actual demand is used instead of the demand forecast [41]. Two types of JIT control circuits are generally used for production management: the KANBAN system and the CONWIP system. The KANBAN system was developed by the Japanese automobile manufacturer Toyota [42]. Pull production controlled by Kanban requires a steady part flow, which is impractical for small and infrequent orders as it is common in the construction environment [43]. More in detail, by using KANBAN in a small lot size and high product variety environment, unused WIP and unresponsiveness of the system is caused because Kanban cards have to propagate backward through the entire line for releasing new orders [43]. Moreover, because KANBAN requires that cards be assigned to parts, this means that at every station just one standard parts container should be placed allowing that a downstream process is able to pull what needed. As a result, an outstanding space needed for placing part containers and an increased complexity to handle the system for non-repetitive manufacturing would be the case. Moreover, a pull based production with KANBAN negatively affects the product mix variety and especially the reduction of batch sizes [44].

However, production in high volumes contradicts the fundamental principle and JIT performance objective of WIP minimization [45]. In contrast, Spearman et al. developed a pull-based production system called CONWIP (CONstant Work in Progress), which can be used in a wide variety of manufacturing environments [46]. A CONWIP production line sets the WIP levels and measures throughput [46]. As the main difference to a KANBAN system, in CONWIP parts are moved by using standard containers, each containing the same amount of work. In CONWIP cards are assigned to these standard containers. The fundamental difference/advantage is that WIP is directly observable while capacity, which is needed to appropriately release work in a push system, must be estimated. According to Hopp and Spearman [46] and Arbulu [47] in a CONWIP production system, on average less WIP levels are needed to obtain the same throughput as in conventional systems. In a CONWIP system, the whole value chain is just triggered in one point (usually the first process step) which improves drastically the handling of the system. Moreover, CONWIP signals are not product specific, which means that with one signal different product types can be triggered in a flexible way [47]. Arbulu [47] suggests quantifying CONWIP signals in time units as opposed to an amount of product units, because this would be more practicable in industry. In Lean Manufacturing, the consistent number of production orders released at the pacemaker process and simultaneously the taking away of an equal amount of finished goods is called "paced withdrawal". Also, in construction, establishing a constant production pace could create a predictable construction flow that would enable quick corrective action to be taken in case of unforeseen problems [5]. In "lean language", this consistent increment of work is called "Pitch" and is calculated by determining how much work can be done at the bottleneck process at a certain and prior-defined interval (i.e., $1 \mathrm{~h}, 1 \mathrm{shift}, 1$ day, etc.) [38]. Therefore, a common unit for the construction flow, independent of the customer order, becomes possible. This "Pitch" becomes the basic unit of the production schedule for the considered product family. For a more detailed explanation of the pitch concept readers could consult the work of Matt [48]. 
The general practice in multi-project management enables work on an incoming project to start immediately as soon as it is commissioned (provided the first relevant resource is available) [49]. According to Anavi-Isakow and Golany [49] this practice is equivalent to the "push" principle in production management, where there is no control over the number of products in the system. In [49] researchers try to adapt the CONWIP principle to multi-project management. They present two variants of the control circuit, one limiting the number of projects and the other limiting the number of worked hours in the system. The concept focuses on a backlog list where projects, arriving at times when the system is unable to accept them, enter an external queue (the backlog list) where they wait until the load of the system has fallen under the threshold. The first variant Constant Number of Projects in Process (CONPIP) limits the number of projects that are allowed in the system to a fixed number. If there are less than the maximum allowed projects in the system, the backlog list is empty and incoming projects are accepted immediately. When the project is activated, it is broken down into its individual tasks. The completion time of an activated project is dependent on the status of the system, because the task has to be ready (all its predecessor tasks have been completed) and the required resource has to be available (not occupied with another task) [49]. The second variant, Constant Time in Process (CONTIP), controls the total processing time required by all the projects that are active in the system. When one task of an active project is completed by one of the resources in the system, the remaining processing time needed for all active projects is updated. When it falls/goes under a certain limit, a new project is allowed to move out of the backlog list and into the active system. Therefore, the second variant considers and controls the available capacity (in terms of labor resources) when activating a new project. One of the results (mentioned in [49]) states that, by holding projects in the backlog list, when the system has reached its capacity, no flow time performance is lost and no accumulation of overhead costs occurs. Moreover, the mentioned pull approach (CONPIP and CONTIP) allows for easier forecasting of completion times. According to [49], many of the synchronization delays, which consist of a task waiting for its predecessor to be completed and which cannot even start since the relevant resources are faced with queues of tasks from other active projects, disappear. The proposed approaches, CONPIP and CONTIP, address the problem of synchronization between different projects.

Carniel-Perrin et al. [50] tried, in their work, to achieve a pull-oriented ERP system in the ETO environment. The high variety nature of the business and the use of ERP systems impact on the ability to implement pull, a term widely misinterpreted. Using the case of a British ETO company, they analyzed and determined the extent to which an ERP can support an ETO to tend towards a "pure" pull system. In their analyses, they focused on the following three principles: (1) KANBAN; (2) CONWIP and (3) POLCA (Paired-cell Overlapping Loops of Cards) methodology.

Gosling et al. [51] derived principles for the design of ETO supply chains, based on the FORRIDGE principles (that are a combination of principles defined by FORRester and BurbiDGE). Forrester [52] emphasized, in 1961, the role of "connectance", feedback and disturbances in manufacturing systems. The more extended the chain, the worse the dynamic response. At around the same time, Burbidge was developing ideas relating to material flow control [53]. The FORRIDGE principles united these different intellectual threads into a succinct set of five principles shown in Table 1 [51]. Gosling et al. analyze how the original principles may be conceived in an ETO environment. A further 'design for $\mathrm{X}^{\prime}$ principle was also added to the original principles shown in Table 1. This is crucial for the ETO supply chain, where companies have to engage in new designs for each customer. This integrates a well-established concept in the design engineering literature with the FORRIDGE principles, thereby expanding and strengthening the principles for use in the ETO sector. Implementing the six principles effectively offers considerable opportunity for competitive advantage for those companies willing to invest. In this way, the paper provides guidance on how to address some of the structural problems outlined in the challenging setting of the ETO sector. 
Table 1. Definitions and influences of the FORRIDGE (FORRester and BurbIDGE) Principles [51].

\begin{tabular}{|c|c|c|c|}
\hline FORRIDGE Principles & FORRIDGE Definitions & FORRester Inputs & BurbIDGE Inputs \\
\hline $\begin{array}{l}\text { 1-Time Compression } \\
\text { Principle }\end{array}$ & $\begin{array}{l}\text { Every activity in the chain } \\
\text { should be undertaken in the } \\
\text { minimum time needed to } \\
\text { achieve task goals. }\end{array}$ & $\begin{array}{l}\text { Faster order handling to } \\
\text { improve stability and } \\
\text { reduction of system } \\
\text { time delays. }\end{array}$ & $\begin{array}{l}\text { Minimize the material } \\
\text { throughput time. }\end{array}$ \\
\hline $\begin{array}{l}\text { 2-Control System } \\
\text { Principle }\end{array}$ & $\begin{array}{l}\text { There is a need to select the } \\
\text { most appropriate control } \\
\text { system best suited to achieve } \\
\text { user targets and take } \\
\text { unnecessary guesswork out } \\
\text { of the system. }\end{array}$ & $\begin{array}{l}\text { Change inventory policy } \\
\text { to adjust the level of } \\
\text { inventories and in } \\
\text { process orders. }\end{array}$ & $\begin{array}{l}\text { Only make those products that } \\
\text { you can quickly dispatch and } \\
\text { invoice to customers-only make } \\
\text { in one period those components } \\
\text { you need for assembly in the } \\
\text { next period. }\end{array}$ \\
\hline $\begin{array}{l}\text { 3-Synchronization } \\
\text { Principle }\end{array}$ & $\begin{array}{l}\text { All events are synchronized } \\
\text { so that orders and deliveries } \\
\text { are visible at discrete points } \\
\text { in time, and there is } \\
\text { continuous ordering } \\
\text { synchronized throughout } \\
\text { the chain. }\end{array}$ & $\begin{array}{l}\text { Events should be } \\
\text { synchronized, so that } \\
\text { orders and deliveries are } \\
\text { visible at discrete points } \\
\text { in time. }\end{array}$ & $\begin{array}{l}\text { Use the shortest planning } \\
\text { period-only take deliveries from } \\
\text { suppliers in small batches as and } \\
\text { when needed for processing or } \\
\text { assembly-demand amplification } \\
\text { can be reduced by continuous } \\
\text { ordering synchronized } \\
\text { throughout the chain. }\end{array}$ \\
\hline $\begin{array}{l}\text { 4-Information } \\
\text { Transparency Principle }\end{array}$ & $\begin{array}{l}\text { Up-to-the minute data free } \\
\text { of "noise" and bias should } \\
\text { be accessed by all members } \\
\text { in the system. }\end{array}$ & $\begin{array}{l}\text { Ensure correct behavior } \\
\text { of information-feedback } \\
\text { systems. }\end{array}$ & $\begin{array}{l}\text { Do not rely on long-term forecasts } \\
\text { and promote "connectance". }\end{array}$ \\
\hline $\begin{array}{l}\text { 5-Echelon Elimination } \\
\text { Principle }\end{array}$ & $\begin{array}{l}\text { There should be the } \\
\text { minimum number of } \\
\text { echelons appropriate to the } \\
\text { goals of the supply chain. }\end{array}$ & $\begin{array}{l}\text { Eliminate distributor } \\
\text { level to reduce demand } \\
\text { amplification. }\end{array}$ & $\begin{array}{l}\text { Efficiency is inversely } \\
\text { proportional to the complexity of } \\
\text { its material flow system. }\end{array}$ \\
\hline
\end{tabular}

As seen also in the works of Anavi-Isakow and Golany [49], Carniel-Perrin et al. [50] and Gosling et al. [51] pull systems can be adapted and introduced in ETO companies to achieve a CSC oriented to the customer demand on the construction site. However, there is still a lack of methods and tools to synchronize off-site manufacturing of ETO-components with installation on-site. Through the adoption of such pull- and JIT-oriented approaches, not only can efficiency in the supply chain increase, but also sustainability of supply chains increases.

\subsection{Research Question}

Based on the introduction and the literature review, the authors define the following two hypotheses and research questions in this work:

RQ1: Is it possible to synchronize off-site fabrication of ETO components and on-site installation by the use of CONWIP?

RQ2: What is the impact of such an approach on sustainability of CSCs in ETO companies?

According to several authors, case research is one of the most suitable ways for the development, testing, disproof and/or refining of a theory or hypothesis $[48,54,55]$ as well as for the determination of further research needs [56], especially in a complex and dynamic context [57]. The previously mentioned research questions are analyzed based on a case study from construction industry.

\section{Analysis of the Actual Situation in an ETO Construction Company}

As mentioned in the introduction, a typical ETO construction project can be subdivided into three main phases: engineering, fabrication and installation. To describe the actual situation in typical ETO CSCs the authors give a short overview of the results of the As-it-is-Analysis at the case study company. The results are categorized into four parts: (1) Project preparation and quotation; (2) Engineering; (3) Fabrication and (4) Installation on-site. 


\subsection{Project Preparation and Quotation}

Before the start of a typical ETO project, the customer or the architect defines the main concept, the customer requirements and the technical specifications. Based on these specifications, an internal project manager elaborates the master plan (usually a macro Gantt chart) where he specifies/estimates the content (work packages), the duration (milestones) for the different phases, and the deadline for the project. Based on this master plan, the ETO-company participates in the bidding process. If the company wins the bidding award, the project enters the multi-project pipeline and the operation work for project realization starts. At this point, the supplier company defines the project team: the project manager, staff from the engineering department, someone responsible for manufacturing and logistics as well as a foreman for the installation team on-site. After the internal project planning, engineering starts with the elaboration of drawings and the technical design. After the realization of the first detailed drawings, manufacturing starts to produce components and parts and the installation crew on-site prepares the construction site for installation.

\subsection{Engineering}

The technical office or engineering puts together the approval design, which consists of a detailed design of the project for customer approval. Usually, the approval design is a 2D or 3D plan, only specifying the overall geometry of the objects. The approval planning is presented to the customer for agreement. When the customer releases the approval design, engineering goes on with shop floor designs. They specify the different components, their design, material, strength requirements and so on. At the same time, the BOM is elaborated, which contains a first estimate of make or buy of components and parts. Based on the BOM and the technical drawings, the project manager, together with quotations from purchasing, defines whether a part is fabricated internally in the job shop or by an external supplier.

\subsection{Fabrication}

Once the make or buy decision process is finished and shop floor designs have been created, they are sent to the production planning department. Production planning integrates the project with multi-project planning and tries to achieve efficiency benefits through the creation of bigger lot sizes collecting production orders from different projects. In some cases, this is necessary to achieve rational economic lot size if the fabrication process requires the use of costly machinery with high changeover times. Furthermore, production planning often tends to increase lot sizes in production through the fabrication of the whole lot size of parts for a single project order instead of JIT-oriented production and delivery. Thus, in many cases, production planning accepts higher production lot sizes and therefore a higher stock of semi-finished and finished components for installation, with the aim of increasing efficiency in manufacturing and very often to overcome risks of a supply shortage and thereby necessary extension of the agreed deadline for the project end. The fabrication ensures then, according to the production planning schedule provided, that all necessary information from engineering (e.g., drawings) and from installation (e.g., tolerances to be determined at the construction site) are delivered on time. Furthermore, the logistics department organizes the transport and supply of the necessary components to the construction site.

\subsection{Installation On-Site}

The installation foreman defines, together with project management, the installation schedule and the installation team (who, where and for how long). Normally, by defining the human resources for projects, learning curve effects should be considered. This means that the uniqueness of every ETO-project requires, at the beginning of every task, a certain time to generate a learning effect for staff. For example, a steel façade installation with a non-repetitive design of façade elements requires some time to optimize the installation tasks for mounting the elements. After some time, the staff become 
more experienced and achieve higher efficiency in the installation of the remaining façade elements. Given the available resources (labor) and a rough experience-based estimation of the learning curve, the installation foreman schedules the assembly process on-site, communicating this schedule to the project manager and production. In many cases, this sharing of information and schedules occurs only at the beginning of a project, while a continuous or periodic re-alignment is often neglected.

\subsection{Findings from Initial Case Study Analysis}

Together with the company, the most important challenges for the research were defined after the initial analysis. The analysis showed that synchronization in planning is lacking between engineering and fabrication, between engineering and installation as well as between fabrication and installation. In order to limit the area of investigation, the focus in this research is on the synchronization between manufacturing and on-site installation. Due to planned changes in the IT environment as well as other circumstances, a more accurate and deeper integration of engineering in the synchronization approach was postponed. Furthermore, the main objectives for the synchronization approach were defined as: (a) a reduction of inventory in the supply chain; (b) the reduction of lead times and thus shorter project delivery times; (c) avoiding budget overruns and increasing profit and (d) increasing sustainability in construction projects.

\section{Conceptual Approach for Synchronization of Off-Site Manufacturing and On-Site Installation in ETO Supply Chains}

The construction industry is generally considered to be some way behind those sectors where effective supply chain management is regarded as key to gaining competitive advantage and dealing with the need to constantly improve operations to satisfy the increasingly sophisticated demands of end users [58]. Since supplier lead times are, for the most part, much greater than the possible accurate foresight regarding work completion on-site, JIT delivery of ETO components from production to the construction site is difficult [59].

In the ETO industry, every product is unique and therefore engineering design, fabrication and installation is made for the specific customer order (batch-of-one production). Even if the final product can involve some standard parts, every customer order requires individual engineering designs and bill of materials, individual production routings and individual installation procedures. Generally, in ETO construction companies, the three phases/departments-engineering, fabrication and installation-are not synchronized with each other. This means that the engineering department produces drawings, which are passed to fabrication. The fabrication department manufactures according to the drawings delivered from the engineering department. Afterwards ETO-components are passed from fabrication to the site for installation. As a result, in the traditional approach, customer orders are pushed from engineering to installation on-site. Therefore, high and uncontrolled levels of WIP occur, which are the main causes of long lead times [60].

The aim of the proposed approach is that ETO-components arrive in the right sequence and quantity needed for installation on-site (Just-in-Sequence (JIS) and JIT). The concept for aligning demand with supply uses the CONWIP regulation circuit (Figure 2). 
Traditional - High and Uncontrolled levels of WIP

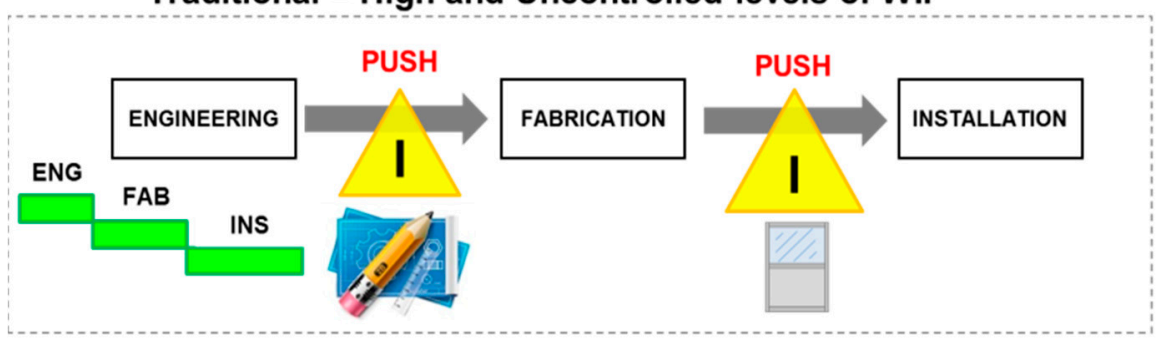

New - Constant Work in Process from Engineering to Installation

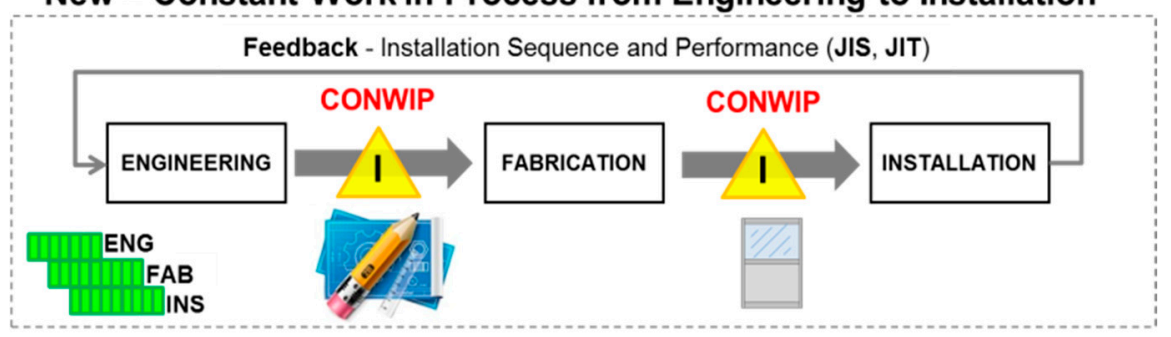

Figure 2. Synchronization approach to align demand with supply (according to [60]).

In this concept, the engineering department defines the optimal installation sequence and performance in collaboration with the installation department. Therefore, the engineering department designs ETO-components in the right sequence needed for installation. Moreover, the right granularity for engineering, fabrication and installation is defined. In detail, the approach consists of two regulation circuits, long- and short-term (Figures 3 and 4) explained in the following Sections 4.1 and 4.2. Here, the customer demand is broken down into small lots of approximately equal size, allowing an optimal capacity saturation and minimal non-productive time. To define those lots with approximately equal size, the so-called pitching concept is used [61]. As shown in Equation (1), for every task, the pitch defines the number of construction areas (CAs), which should be completed by a specific crew in a defined interval. As a practical example, consider façade installation and specifically the task installation of frames, where four CAs, consisting of four rooms, should be completed by a crew composed of two workers in a day.

$$
\text { Pitch }(\text { task })=\# \text { CAs } / \text { crew } / \text { time-unit }
$$

The pitching concept is used to structure the work in the long-term as well as a short-term control loop (Figures 3 and 4). Pitches that are composed of different services are interpreted in the construction industry like containers in the manufacturing industry incorporating physical products.

\subsection{Long-Term Control Loop-Multi-Project Level}

The long-term control loop is used to define the optimum number of projects in the production system (Figure 3). In the CONWIP-backlog, the Master Schedules of different projects are combined to calculate the necessary work capacity. Furthermore, the final aim of the CONWIP-backlog is to define the optimal sequence of different projects according to the delivery time. If construction delays occur, the project sequence has to be recalculated in the CONWIP-backlog avoiding a scenario where components are produced too early and must, therefore, be stored throughout the supply chain or on the construction site. The project orders throughout the phases/departments-engineering, fabrication and installation-are structured according to the pitching principle. As a result, one pitch flows from engineering to the site for installation in a continuous way (One-Pitch-Flow). Of course, the granularity to define pitches in the long-term control loop should be at a lower level (e.g., weeks, months). In the lower part of Figure 3, the multi-project capacity planning is shown. The time frame was set at a 
weekly detail just to demonstrate the concept. In the middle of the figure, the time scheduling is shown. The time schedule contains the pitches from engineering, fabrication and installation, which have to be scheduled to reach the milestones defined in the project contract. Furthermore, pitches visualized in green define project No. 1 and pitches visualized in gray define project No. 2. The optimum level of WIP (in terms of number of pitches) is defined according to the law of little [62]. The best case is when the WIP level consists of 3 pitches and a lead time (LT) of 3 calendar weeks (CW) can be guaranteed to the customer, resulting in a throughput (TH) of 1 pitch/CW (Figure 3). This level of WIP is called the critical WIP $\left(\mathrm{WIP}_{\mathrm{C}}\right)$. If the level of WIP is below the WIP $\mathrm{P}_{\mathrm{C}}$, the system does not work at full capacity, which means that an output of $2 / 3$ pitches/CW is reached. If the level of WIP is greater than the $\mathrm{WIP}_{C}$, the lead time increases and the promised delivery time cannot be guaranteed to the customer. Therefore, according to the CONWIP principle, when the pitch-Installation-A is finished, the pitch-Engineering-D can enter the system. If the pitch-Installation-A could not be finished in $\mathrm{CW} 3$, then the project sequence in the backlog has to be recalculated and, instead of pitch-Engineering-D, the pitch-Engineering-E should be released. Moreover, in CW 4 not pitch-Fabrication-D, but the pitch-Fabrication E should be released avoiding a scenario where components are produced which cannot be installed immediately, overfilling the buffer for storing material on-site.

As described in [49], every project is broken down into its individual tasks and the necessary labor resources are assigned. Therefore, in comparison to the traditional approach, employees for installation are planned in advance avoiding a switch between different projects and between fabrication and installation. Furthermore, the necessary work capacity (for new projects) can be calculated and compared with the available capacity used in running projects. Important milestones within the three phases (engineering, fabrication and installation) should be set, which take into account the available work capacity. As a result, new projects can be sequenced in an optimal way to reach the defined milestones. The long-term control loop uses the CONWIP approach to determine when a new project can enter the system by taking account of the available work capacity.

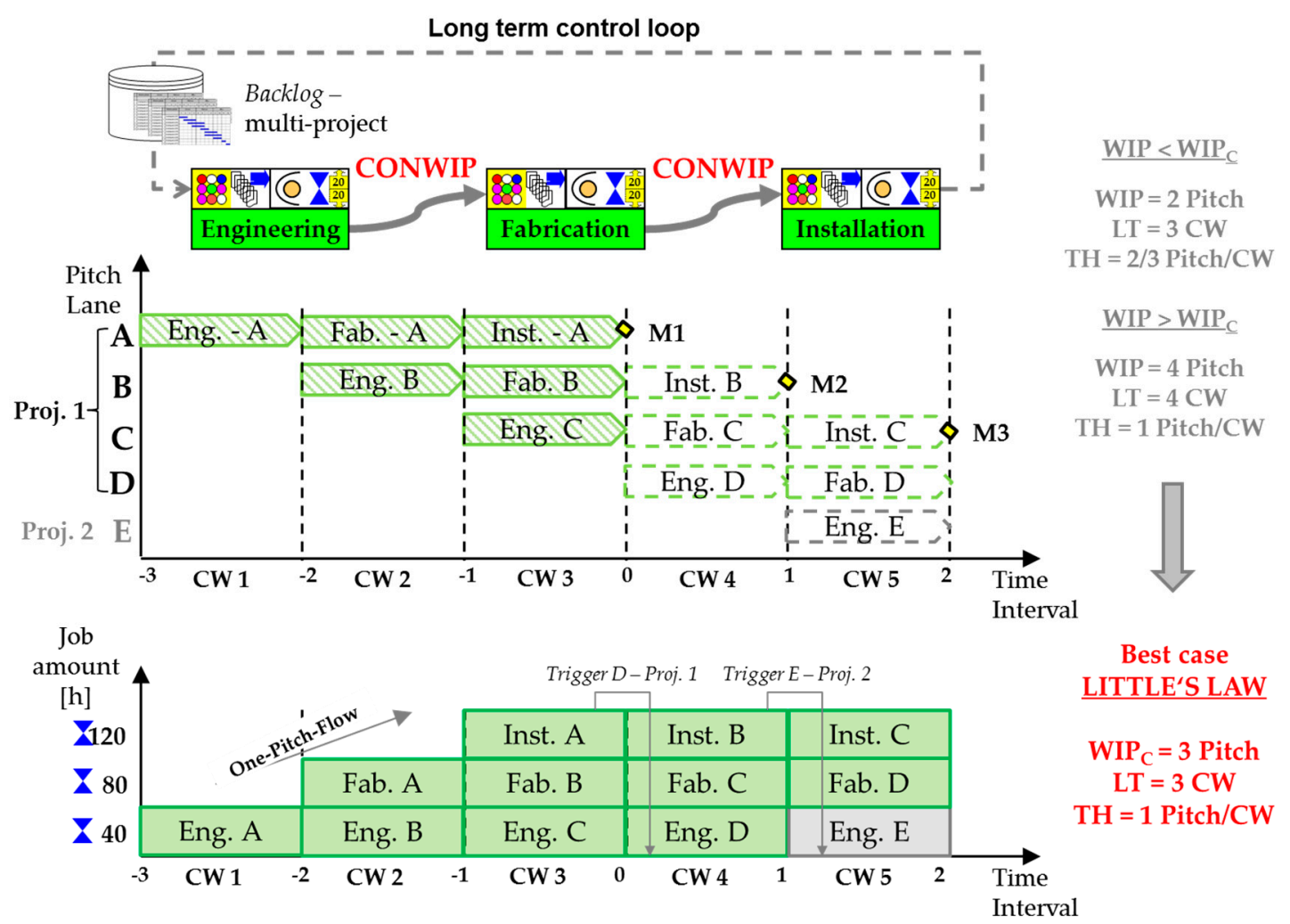

Figure 3. Long-term control loop-multi-project capacity planning. 


\subsection{Short-Term Control Loop-Project Level}

The short-term control loop is used to schedule and control the work to be performed within the supply chain and on the construction site for the upcoming time interval (Figure 4).

In the short-term control loop, an appropriate granularity should be defined in engineering, manufacturing and installation. The same granularity means, in this case, that a Constant Work in Progress (e.g., work for one week or one month) flows from engineering to installation. As visualized in Figure 4, the job amount for engineering, fabrication and installation is different. It depends on the tasks to be performed and, accordingly, on the necessary workforce for each phase. This is different from the conventional assumption where CONWIP is used in manufacturing and parts are moved by using standard containers each containing the same amount of work [46]. In this context, the work to be performed in the three departments is very different (in terms of job type). As a result, the three departments are not balanced in terms of the same job amount avoiding the slowing down of departments due to a different job type. As practical example, if two employees working full-time (FTE) produce shop floor drawings in one week, two employees in production would not be able to produce all the components specified in the shop floor drawings in the following week (usually production takes longer or it needs a larger workforce than engineering). In the proposed approach, the time unit remains constant but the job content for the pitches of the three departments varies (Figure 4). To measure the project performance, the physical part of the building where tasks have to be performed (the CAs), are used. As a practical example, in the case of façade installation (as visualized in Figure 4), CA1 could be the east façade of the fourth floor. In more detail, the engineering department should produce shop floor drawings, which contain a complete CA. Most of the time, due to lack of time, shop floor drawings are produced for the main parts (e.g., east façade of fourth level) and details (e.g., connection east and west façade) are missed and defined at a later stage. Therefore, necessary components for completing a construction area will not be produced and delivered at the right time. This means that there is left over work still to do on-site. In order to complete the remaining work on-site, a higher amount of work in comparison to the normal amount is needed.

Every department works with a self-regulation control loop. This means, if the work for one time interval (e.g., one CW in Figure 4) cannot be completed, the work capacity should be increased. In principal, this could be done in two ways: (a) increasing the size of the workforce by using temporary employees or (b) increasing the working time by introducing overtime. As visualized in Figure 3, pitch A has to be completed before pitch B can be started. As a practical example, if pitch A is not going to be finished in one CW (5 days), overtime will be introduced, which means that the employees responsible for pitch A will also work on Saturday (6 days). As a result, the system will work with a capacity flexibility of $\pm 20 \%$.

To identify in time if a pitch will not be completed according to a specified deadline, a detailed measurement of its tasks is carried out. In frequent time intervals (e.g., daily frequency), the progress of tasks within the three departments is measured (e.g., number of elaborated shop floor drawings, number of produced components and number of completed CAs).

As a result, by limiting the amount of WIP in the system and by using the long-term as well as the short-term control loop, two positive effects can be reached: (1) an over allocation of projects in the system and thus an overloading of employees is prevented and (2) by using the short-term control loop, a delay in predecessor tasks causing a delayed start to successor tasks is avoided. 


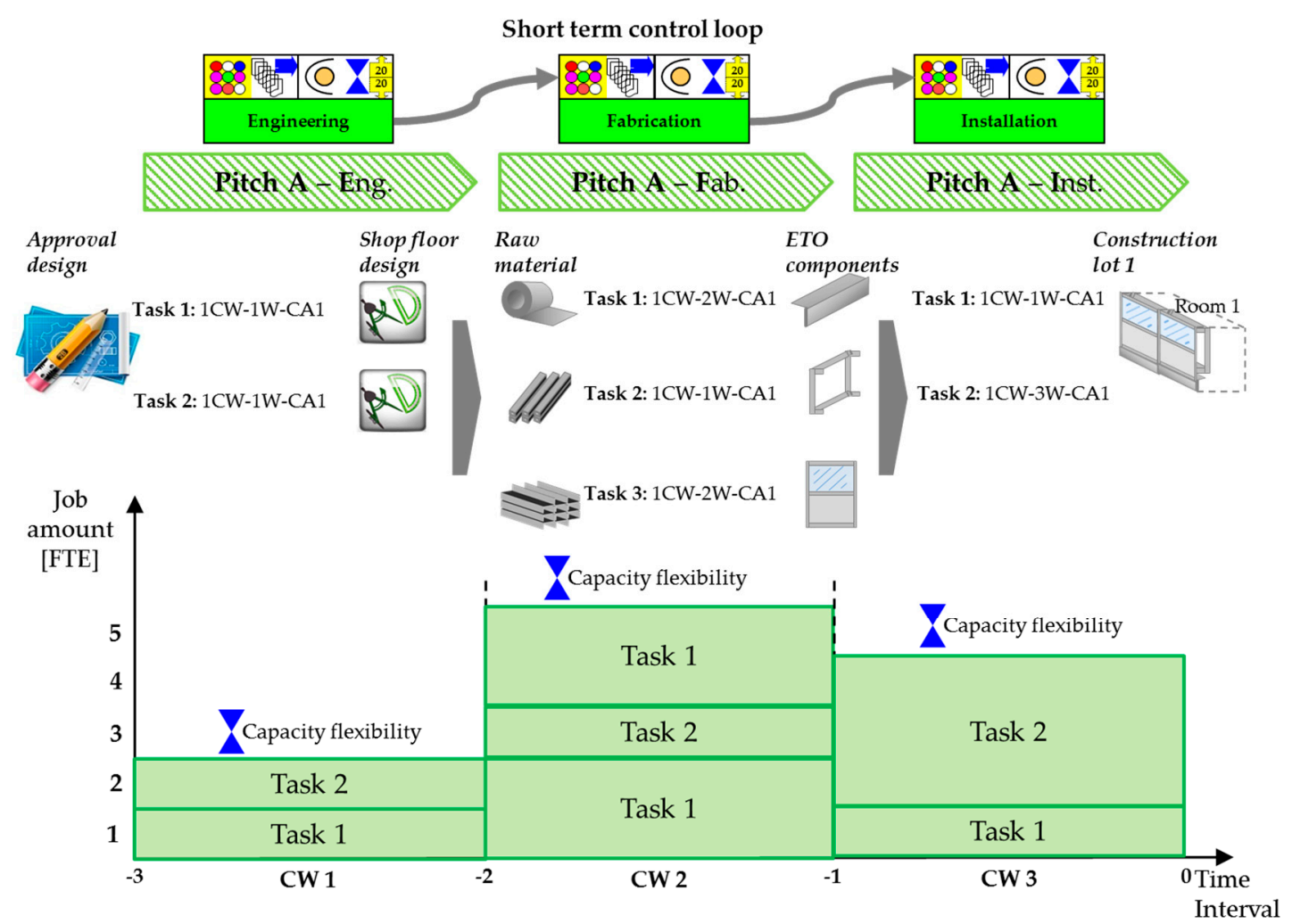

Figure 4. Short-term control loop-synchronization of engineering, fabrication and installation.

\section{Validation of the Proposed Synchronization Approach in an Industrial Case Study}

In order to answer the research question RQ1 ("Is it possible to synchronize off-site fabrication of ETO components and on-site installation by the use of CONWIP?") the proposed approach was validated in an industrial case study.

The approach was tested in collaboration with the previously mentioned ETO façade supplier company applying it to the extension of a new bedroom block in a hospital construction project. The construction project consists over ground of three wings (A, B and C) with respectively four levels, and a new entrance area. The considered ETO façade supplier company realized as Leader Company in a bidder-consortium the facades of the three wings. The facades were designed according to the conventional building technique, the so-called mullion-and-transom system where every single component is delivered separately to the site and will be assembled on the spot. As a special restriction, a small buffer consisting of around $100 \mathrm{~m}^{2}$ for storing material on-site was available to the ETO façade supplier company.

The construction site started on calendar week CW16-2013 and finished on CW50-2014. The researchers were only involved in the project from CW46-2013. This was because the project management recognized an abnormal consumption of budget which was non-compliant with the planned construction progress up to that point in time.

At the beginning, collaborative workshops were performed, in which the project manager, the foreman on-site and the responsible employee from the design office participated. First, the building was structured in CAs where a specific codification was developed (Figure 5). The sector indicates which wing ( $\mathrm{A}, \mathrm{B}$ or $\mathrm{C}$ ) of the construction project is considered. According to every sector the level (from one to four) and the orientation (east, north, west and south) is specified. The highest level of detail of a CA is defined by its construction units (CUs), specified as the distance between two principal axis of the building. The definition of CUs showed several benefits: (1) every CU has more or less the same size (around 7-8 m); (2) the separation of CUs is visible on-site because every CU is 
delimited by two pillars and (3) CUs were small enough that a detailed and reliable measurement of the construction progress could be performed every day.

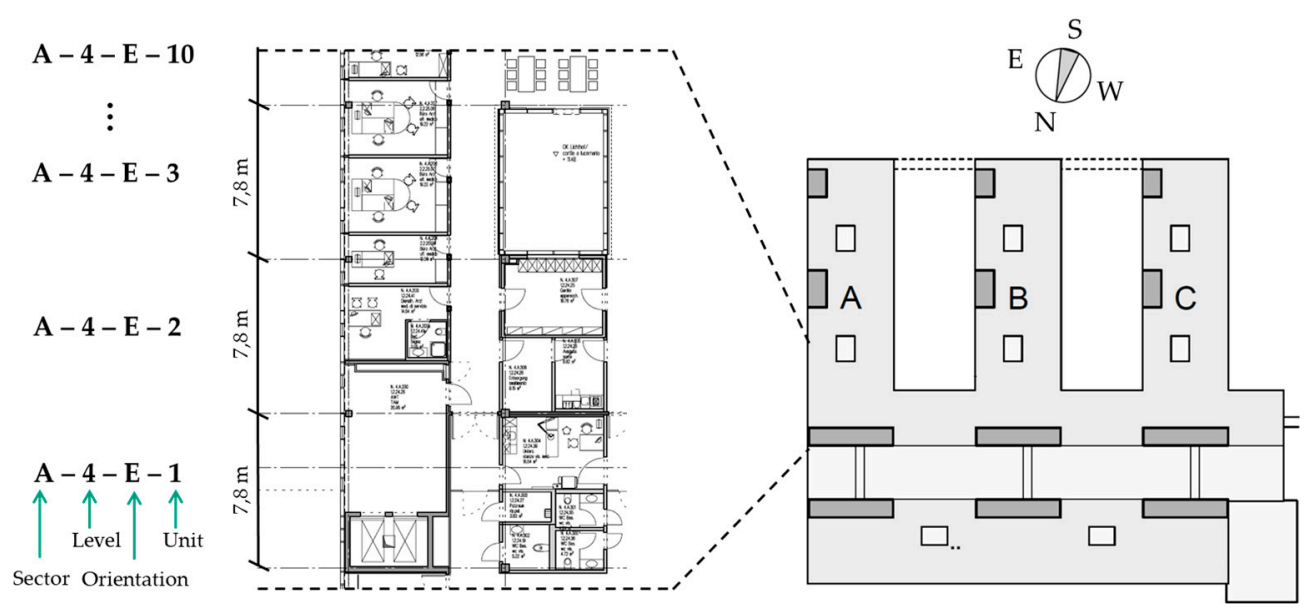

Figure 5. Definition of construction areas (CAs).

Figure 6 shows in detail the applied approach for synchronization of the manufacturing process with the installation on-site. Based on the drawings approved by the customer, the necessary tasks on-site were defined and the foreman estimated the pitch for every task. By taking into account the pitch and the total amount of CAs where the task had to be performed, the duration was calculated and, by taking into account the crew in terms of necessary workforce size, the job amount in man-hours was calculated. As a practical example, consider again the task "installation of frames" for which a pitch consisting of 4 CAs of the east façade (four CUs) to be performed by a crew consisting of 2 employees working $8 \mathrm{~h}$ /day was estimated. The east façade task "installation of frames" should, in this case, be performed in $50 \mathrm{CAs}$ and, as such, a duration of 12.5 days (50 CAs/4 CAs/day) resulting in a job amount of 200 man-hours was calculated (12.5 days $\times 2$ workers $\times 8 \mathrm{~h} /$ day).

This calculation was performed for every task and the job amount was calculated resulting in a budget for value-adding tasks, Budget $t_{v a}$. To calculate the total budget to complete the installation on-site, the budget needed to include supporting tasks, Budget $t_{s u}$, which included tasks such as logistics and site management. To calculate the amount of man-hours needed for Budget $t_{s u}$ the foreman estimated

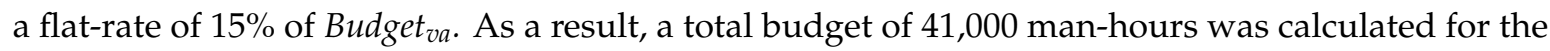
project (see Figure 7).

Furthermore, as shown in Figure 6, the pitch was also used to synchronize the fabrication shop with the construction site. Here, for every task to be performed in a specific CA, the necessary component groups were defined. This was done once the engineering department had produced shop floor drawings. In more detail, in the fabrication shop, the work structure for producing the single components, based on the installation structure on-site, was established. Here, a fundamental distinction between lot-based prefabrication and a final assembly of semi-finished components was made. Consider again the task "installation of frames", which requires a certain number of frames per $\mathrm{CA}$, and specific tasks needed to produce single components in the fabrication shop. Here, specifically the cutting of profiles, their welding to frames and the drilling and painting as finishing operations were considered (Figure 6). Based on the assignment of component groups to tasks, a demand-driven release from the construction site could be achieved (upper part of Figure 6). Every week, the foreman on-site scheduled the tasks to be performed for the upcoming CW. This was done based on the progress made in the construction up to that point, in terms of completed CAs. Simultaneously to the weekly work scheduling, the foreman on-site performed a medium-term scheduling of tasks used to release the required component groups from the fabrication shop. This medium-term scheduling period consisted 
of four weeks, because the foreman stated that he was not able to predict the tasks to be performed on-site more than four weeks ahead. In order to release the component groups that have a lead-time longer than four CWs, a supermarket was installed at the fabrication shop to buffer prefabricated and semi-finished components. These components had been prefabricated according to the master schedule of the company and by taking into account the inventory level in the supermarket.

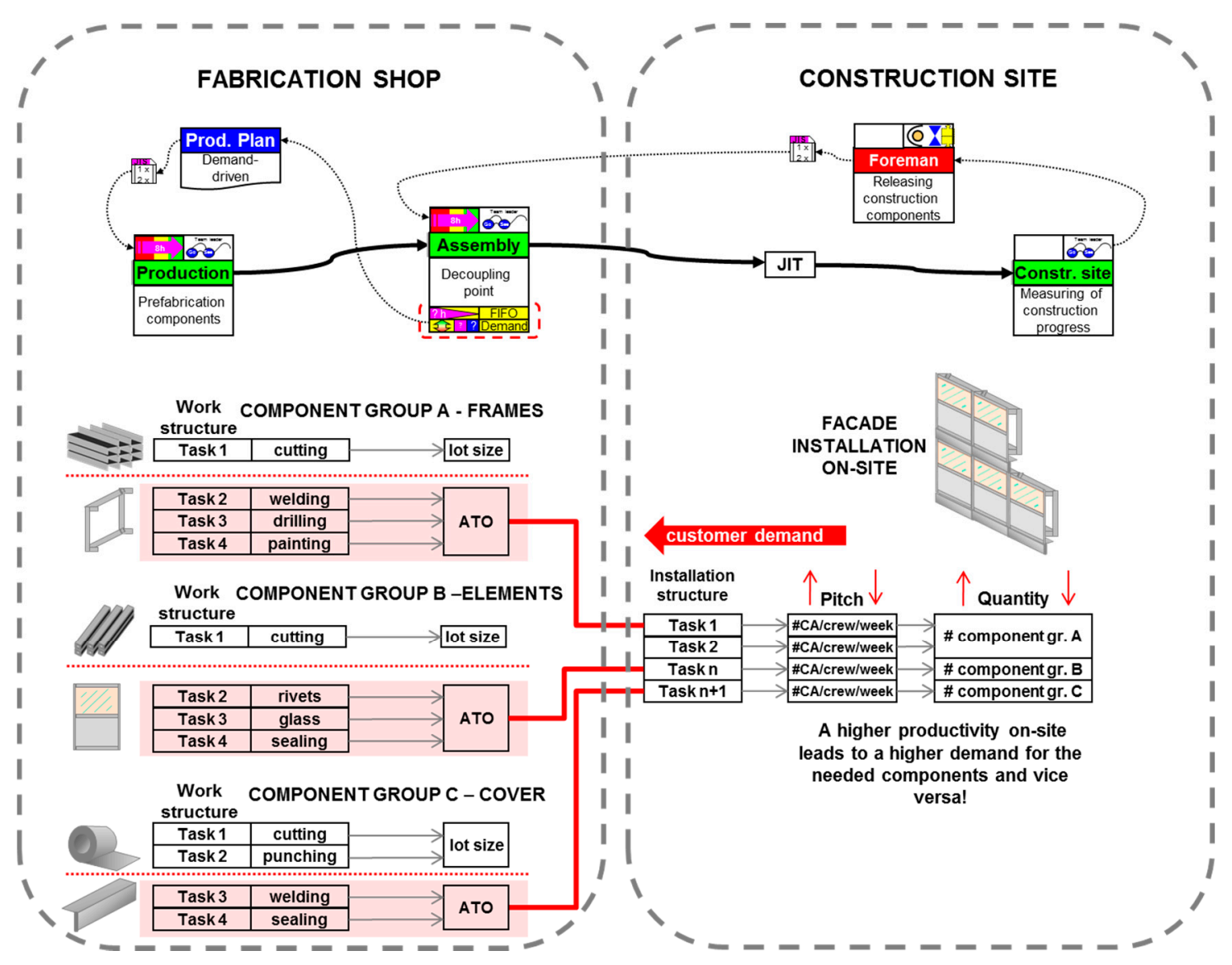

Figure 6. Synchronization of the fabrication shop with the construction site (based on [59]).

As a result, a pull-based production system, taking into account the demand of the construction site could be implemented. To validate the synchronization approach, a specific diagram, displaying the up to date consumed budget in terms of man-hours and the corresponding forecast was developed. It is displayed in Figure 7, where the bars in light gray show the cumulated consumed budget (in man-hours) and the bars in dark gray illustrate the forecast for the necessary job amount in every CW. Equation (2) displays the calculation of the forecast. Every week a comparison of the cumulated consumed budget and the forecast until project completion was computed.

$$
\text { Forecast }_{(t)}=\left[\left(1-\text { Closed CUs }_{(t)}\right) * \text { Budget }_{v a}\right]+\text { Budget }_{s u(t)}+\text { Budget }_{c o(t)}
$$

The term Closed $C U_{(t)}$ refers to the amount of completed CAs (until time $t$ ) in relation to the total amount of CAs where a specific task has to be completed. As a practical example, consider again task "installation of frames" planned to be performed in $50 \mathrm{CAs}$ in total; up until a specific $\mathrm{CW}_{(t)}$ a quantity of $30 \mathrm{CAs}$ had been completed resulting in a value of 30/50 Closed $\mathrm{CU} \mathrm{s}_{(t)}$. The term Budget $\mathrm{cos}_{(t)}$ refers to cumulated reported working hours by the installation crew on-site up to a certain time. As anticipated previously, the Budget $t_{v a}$ was calculated using the pitch estimated by the foreman during the collaborative workshops (mentioned in the previous paragraphs). If the pitch as performance 
target is increased, than the Budget $t_{v a}$ and the Forecast $(t)$ will be decreased and vice versa. Figure 7 visualizes the juxtaposition of the cumulated consumed budget in man-hours (light gray bars) up to a certain week, the forecast until project completion (dark gray bars) and the total budget limit defined during the collaborative process planning workshops (black line). As visualized in the plot, at the beginning of the validation period, the forecast exceeded the total budget limit. This was because, at the beginning, the research team experienced problems in applying the material request on-site resulting in construction interruptions due to missing materials. From CW03-2014, the synchronization of the fabrication shop to the site began to work and, therefore, the forecast could be steadily reduced. Moreover, the continuous adaptation of pitches to the real conditions on-site allowed reliable material requests and forecasts of the necessary man-hours until project completion to be made if forecast increases happened, as in CW23-2014 or CW28-2014, the plot allowed them to be identified early on and improvement actions to be implemented in time.

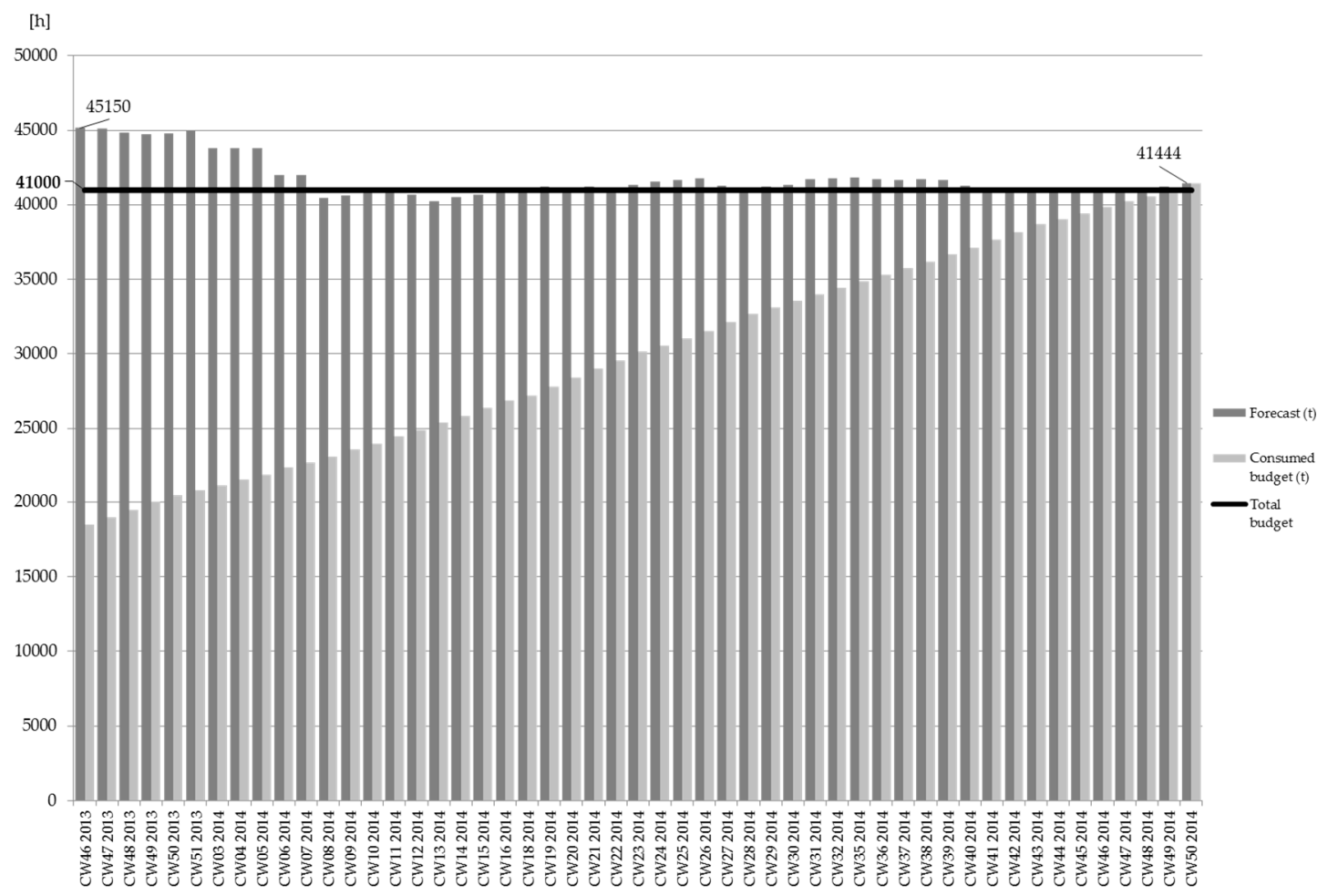

Figure 7. Overview of consumed budget vs. forecast until project completion.

As visualized in Figure 7, the approach allowed the amount of man-hours needed to perform the installation on-site to be reduced from $45,150 \mathrm{~h}$ (predicted at CW 46-2013) to $41,444 \mathrm{~h}$ actually used up to the end of the project. In other words, by applying the approach for synchronizing manufacturing to the installation on-site, a reduction of the initial forecast of around $8 \%$ could be reached. In conclusion, the application of the approach allowed the cost for installation to be kept within the total budget limit. Thus, the answer to RQ1 is that the proposed approach is suitable for synchronizing off-site fabrication of ETO components and on-site installation using CONWIP. Therefore the algorithm had a significant impact to react rapidly on budget overruns and thus to avoid an economic loss in this project. Through a higher accuracy in JIT delivery based on the presented approach the deliverability rate of material for the construction site could be increased by $17 \%$. In the past, the case study company rented very often a production hall with $1000 \mathrm{~m}^{2}$ close to the company's fabrication shop and used the space as buffer stock for material waiting for shipping to the construction sites. The management was already thinking about expanding the company's building, using free agricultural land. Through 
the application of the algorithm, the need to rent these spaces was reduced to sporadic leasing in case of urgent bottlenecks. Therefore, in the case study initially the company planned to lease an intermediate inventory with a capacity of $1850 \mathrm{~m}^{2}$. However, the management board decided to apply the presented approach and as such to avoid an intermediate storage and ship directly the needed components to the site. As a result, costs for loading and unloading trucks, costs of insurance of the inventory as well as transportation costs from the inventory to the construction site could be avoided. In total, $5.29 \%$ of the budget available for installation could be saved by avoiding an intermediate storage and applying direct deliveries to the site. Such a reduction of space has not only an economic impact, but also an ecological impact with the meaning of lower energy consumption for lighting or heating/cooling and less waste of agricultural space. As another important consideration for economic sustainability, a quantitative evaluation of the effort needed in using the approach was carried out. Here, the effort needed for performing the collaborative planning workshops (to define CAs, tasks and pitches), the effort for scheduling and reporting the work to be performed on-site, as well as the expenditure of time for releasing ETO-components JIT for installation was considered. As a result, an amount of 571 man-hours was calculated and by comparing it with budget a percentage of $1.39 \%$ resulted. More in detail, an expenditure of 571 man-hours allowed to decrease the total labor forecast of 3700 man-hours or in other words a saving factor of $6.47(3700 \mathrm{~h} / 571 \mathrm{~h})$.

Considering the ecological sustainability dimension, the use of express delivery services decreased by more than $70 \%$ compared to other projects in the past. As main reason for this positive effect, the project manager stated that the implementation of a weekly release of needed components allowed to assure that they were most of the time available on-site. Express deliveries were just used in the case of engineering and fabrication errors. While in the past rework on the construction site was very common, the amount of rework after the introduction of the synchronization approach could be reduced by $33 \%$. According to the foreman, this reduction was mainly possible because the synchronization of the fabrication shop with the construction site allowed to use smaller lot sizes and as such if errors were identified on-site just the components of the released amount had to be reworked (not the total amount of needed components in the project). As rework of customized parts means in most of the cases that parts have to be substituted (e.g., sealing components or glass elements), the impact on ecologic sustainability is significant.

Considering the social sustainability, an important result was the less fluctuation of the number of assigned operators on-site. Due to a better planning of labor resources at the multi-project level a frequent exchange of operators between different construction sites and between the fabrication shop and the sites was diminished. Throughout the entire lifecycle of the construction site a number of 11 until 13 operators were present on-site. More in detail, as visualized in Figure 7 the bars in light gray, visualizing the consumed budget every week, increased steadily (from $440 \mathrm{~h} /$ week to $520 \mathrm{~h} /$ week) until project completion. Today, the case study company uses this approach in most of their important and international projects. From a social aspect, the proposed approach increases the know-how of workers and supervisors at the construction site. In order to guarantee a successful roll-out of the approach, the company hired qualified staff, trained these people in the approach and created an own department for synchronizing the different installation sites to the fabrication shop (called as Supply Chain Management department). These trainers now train the project managers and supervisors at the construction site in applying the presented approach. These lead also to a job enrichment of workers and thus to a higher involvement and identification with the employer.

The quantitative results in this case study, having impact on economic, ecological and social sustainability, are summarized in Table 2 . 
Table 2. Impact of case study results on economic, ecological and social sustainability.

\begin{tabular}{|c|c|c|}
\hline Economic Sustainability & Ecological Sustainability & Social Sustainability \\
\hline $\begin{array}{l}\text { - } \\
\text { - }\end{array} \begin{array}{l}\text { Increase of material deliverability of } 17 \% \\
\text { Avoiding of an intermediate storage with an } \\
\text { initial calculated cost of } 5.29 \% \text { of } \\
\text { installation budget } \\
\text { acceptable effort needed to use the approach in } \\
\text { practice (1.39\% of the installation budget) } \\
\text { Factor effort saving } 6.4\end{array}$ & $\begin{array}{l}\text { - } \quad \begin{array}{l}\text { Reduction of express and special transports of } \\
\text { more than } 70 \%\end{array} \\
\text { Reduction of rework of components on-site } \\
\text { about } 33 \% \\
\text { - Avoiding of an intermediate storage capacity of } \\
1836 \mathrm{~m}^{2} \text { and thus no more need of an extension of } \\
\text { the factory on agricultural land }\end{array}$ & $\begin{array}{l}\text { - Less fluctuations of the number of operators } \\
\text { on-site (from } 11 \text { to } 13 \text { workers) } \\
\text { Creation of } 2 \text { new jobs in form of on-site } \\
\text { process optimization } \\
6 \text { project manager and } 5 \text { foremen trained in the } \\
\text { application of the new approach and algorithm }\end{array}$ \\
\hline
\end{tabular}




\section{Discussion of the Impact on ETO CSC Sustainability}

In this section, the findings in Section 4 (proposed synchronization approach) and Section 5 (validation in practice) based on the case study research are generalized and summarized. Before starting with the description of the impact of the proposed approach on sustainability, the term sustainability itself is explained.

Sustainability is part of the optimization of the overall efficiency of enterprises, products and processes. Sustainability traditionally has three dimensions: economy, ecology and social. Costs of energy or materials have an impact on the economic effectiveness. The reduction of resources is a contribution to the economic and ecological effectiveness. The social dimension is represented by work conditions, conditions of education, skills and others [63] (Figure 8). Based on these three dimensions, different aspects and arguments for why the presented approach for synchronization will positively affect the sustainability of construction supply chains in the future are shown.

The application of Lean and JIT in ETO companies leads to more sustainability in their supply chain. Our algorithm described in Section 4 and tested in Section 5 supports ETO manufacturer in the construction industry to overcome difficulties in implementing this concepts in a holistic manner focusing not only lean aspects in the fabrication, but focusing on the synchronization with on-site installation. Previous to this case study, the company tried to implement lean methods in production as well as to conduct Kaizen workshops at the installation site. Both initiatives did not lead to the expected results before synchronizing them and thus introducing a customer pace from installation to manufacturing. In the following Sections 6.1-6.3, the proposed approach will be discussed based on the three dimensions of sustainability. Table 3 summarizes the results and advantages of the approach in terms of a more sustainable CSC in ETO companies in order to answer to research question RQ2 ("What is the impact of such an approach on sustainability of CSCs in ETO companies?").

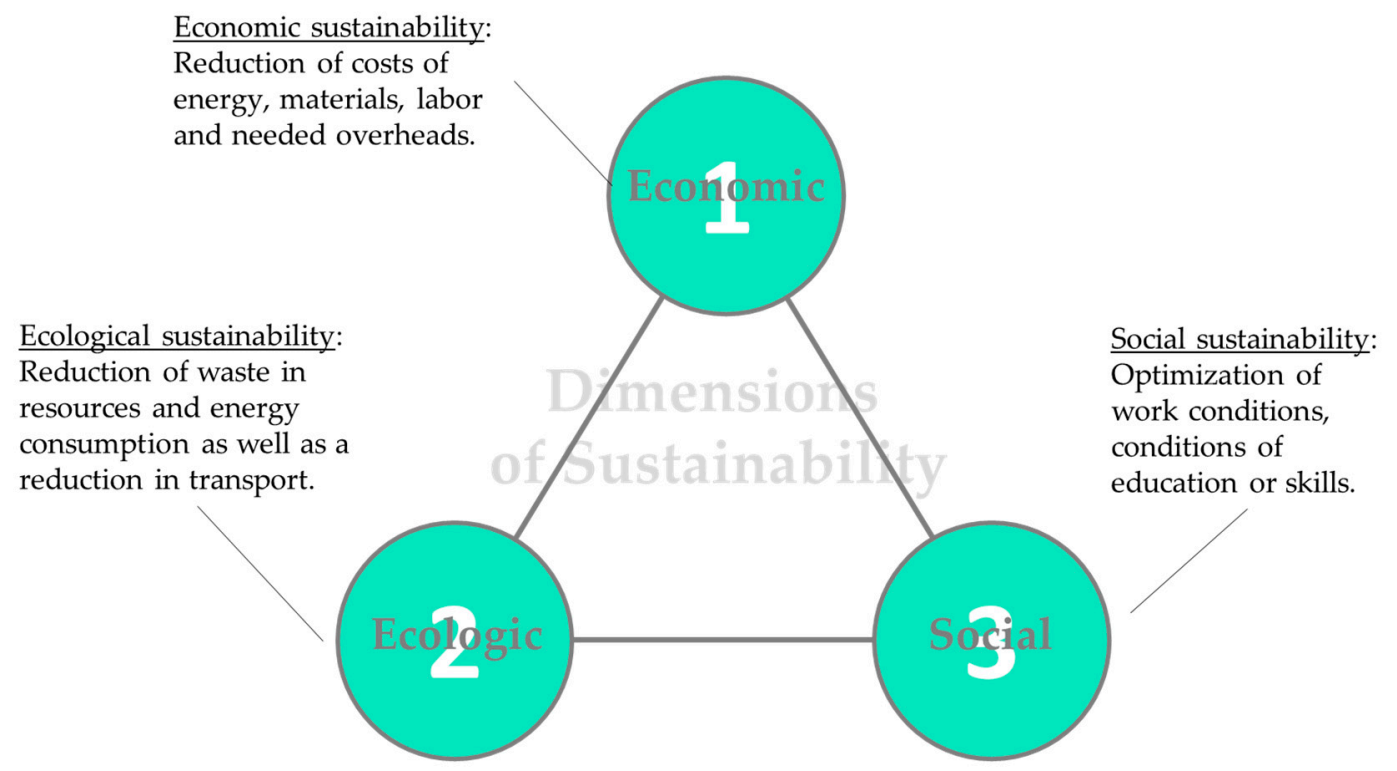

Figure 8. Dimensions of sustainability (adapted from [64]).

\subsection{Economic Aspects}

The economic aspects in the adoption of the proposed synchronization approach are varied. Firstly, the proposed approach to synchronize manufacturing and on-site installation enforces a cost-efficient coordination, saving time for information sharing and organization and thus costs for supporting activities. As seen before, different types of waste can be reduced saving costs and thus being more attractive to the market and/or increasing profitability for the ETO-company. The reduction 
of waste in overproduction is reached through a customer-driven triggering of production. In this way, manufacturing produces only the amount needed in a given time period at the construction site. This also leads to a reduction in transportation costs due to an improved coordination of material and logistic flows. At the same time, JIT production and delivery also reduces inventory and material buffers at the production site and at the construction site, saving costs for space and material handling. Especially on the construction site, space is always limited and costly (particularly in urban areas). As shown in Figure 7, the budget overrun identified at the beginning (starting by CW46-2013 until CW03-2014) was mainly caused by non-synchronized material deliveries. The delivery of components too early caused an overfilling of the buffer on-site inducing the following types of problems: (a) buffering of components on-site over a longer period caused the risk of damages and therefore reworks; (b) searching and moving of components in the buffer caused an abnormal high amount of supporting work. A delivery of components too late caused that the foreman had to reschedule the work on-site. In the worst cases, if a rescheduling could not be done, costly construction interruptions happened. A rescheduling of work due to missing material caused that some CAs had to be completed in a second moment, which required a higher amount of work (supporting and value adding) due to a rearranging of tools and initial learning curve effects because of a restarting of the work. As a result, the approach allowed avoiding missing material on-site and as such a reduction of downtimes and waiting times, and therefore increases in construction productivity. This allowed to decrease the initial forecasted budget overruns and a staying on budget until project completion.

\subsection{Ecological Aspects}

Transport between the fabrication shop and the construction site generate an increase in $\mathrm{CO}_{2}$ emissions and, therefore, environmental pollution. Bearing in mind the finite resources of fossil fuel and energy, the reduction of unnecessary transport helps protect the environment. The application of the proposed approach in ETO supply chains will reduce traffic on the road, which is a positive aspect for flora, fauna and human society considering noise nuisance and air pollution. A more transparent and better coordinated synchronization of transport between manufacturing and installation on-site not only brings benefits to transport but also in terms of energy consumption for material handling devices. A high inventory level off-site or on-site requires a rearrangement of material due to limited space that could be eliminated or minimized by the introduction of JIT and JIS production and direct supplies to the site. In the case of poorly coordinated manufacturing and installation, parts and components are made to stock. If changes in the geometry of parts are then required due to special situations during the installation, the material stock which has been produced has to be disposed of. This means that waste in material consumption and non-value adding activities not only have an economic, but also an ecological impact. A further aspect is that space is always limited at the fabrication site and at the construction site. A reduction in inventory levels also reduces the need for new space which is very often found in green areas.

\subsection{Social Aspects}

The proposed approach not only has economic and ecological advantages, but also offers benefits from a social point of view. Better-synchronized coordination leads to increased employee satisfaction and, therefore, lower staff turnover. High transparency in the supply chain also reduces conflict situations between manufacturing and installation on-site. This means there are fewer "emergency" situations, less stress for employees and more time to think about strategic optimization. In addition, the proposed approach also requires highly skilled and qualified personnel for coordination and monitoring of the progress at the construction site. It also enforces the creation of new job profiles, in terms of engineers for process optimization in ETO supply chains and at construction sites. Successful ETO-companies using this approach to optimize their supply chain usually have a competitive position in the market and, therefore, they will create new jobs. 
Table 3. Generalized impact of the proposed approach on sustainability in ETO CSCs.

\begin{tabular}{|c|c|c|c|}
\hline Economic Dimension & Ecological Dimension & Social Dimension & Future Challenges \\
\hline 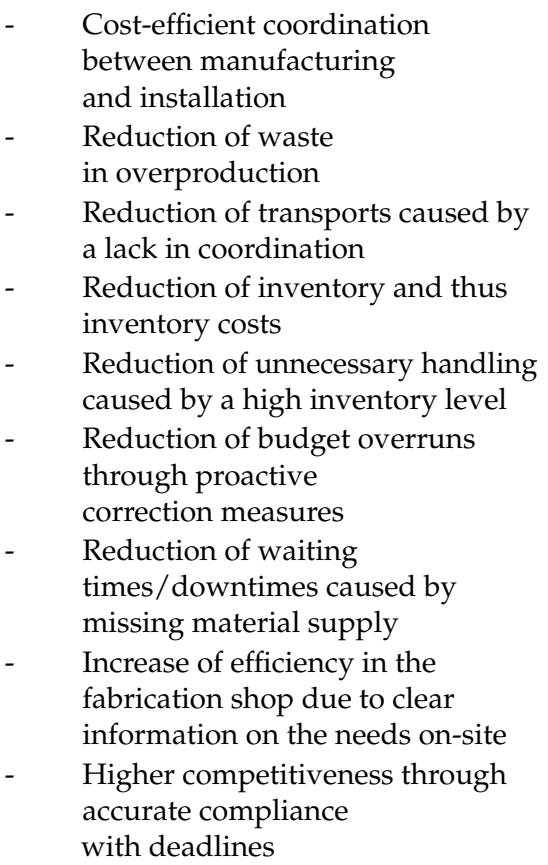 & $\begin{array}{l}\text { Reduction of material waste due to } \\
\text { bad coordination of manufacturing } \\
\text { and installation } \\
\text { Reduction of energy consumption } \\
\text { for material handling devices to } \\
\text { handle material stock off-site and } \\
\text { on-site due to limited space } \\
\text { Reduction of energy consumption } \\
\text { due to express transports caused } \\
\text { through a lack of coordination } \\
\text { Reduction of space needed for } \\
\text { material buffers off-site and on-site }\end{array}$ & $\begin{array}{l}\text { - } \begin{array}{l}\text { Improvement of employee satisfaction } \\
\text { through synchronized coordination }\end{array} \\
\text { Higher transparency in the supply } \\
\text { chain and thus fewer conflicts between } \\
\text { manufacturing and the site } \\
\text { - Fewer "emergency" situations in } \\
\text { material supply and thus less stress } \\
\text { situations for employees } \\
\text { Necessity of highly skilled and } \\
\text { qualified personnel for coordination } \\
\text { and to monitor the progress on-site } \\
\text { Job creation in the sense of new job } \\
\text { profiles for process optimization in } \\
\text { ETO supply chains } \\
\text { Higher employment rate in growing } \\
\text { and successful ETO companies using } \\
\text { this approach to increase } \\
\text { competitiveness in lead times }\end{array}$ & $\begin{array}{l}\text { Education of highly skilled process } \\
\text { engineers with a focus on efficient and } \\
\text { sustainable supply chains } \\
\text { ( } \rightarrow \text { universities and schools) } \\
\text { Development of an IT tool to } \\
\text { implement the proposed approach in } \\
\text { the sense of the actual trend in } \\
\text { Industry } 4.0 \text { and } \\
\text { Cyber-Physical-Systems ( } \rightarrow \text { research) } \\
\text { Extension of the approach to the } \\
\text { coordination of different companies } \\
\text { on-site and the respective } \\
\text { supply chains } \\
\text { Application of the approach and the } \\
\text { IT-tool in practice to evaluate results } \\
\text { and to improve it }(\rightarrow \text { further case } \\
\text { studies in industry) }\end{array}$ \\
\hline
\end{tabular}




\section{Conclusions and Outlook}

One of the major causes of budget overruns is the lack of ETO-components on-site, which causes wasteful construction downtimes. When construction interruptions occur, tasks on-site have to be rescheduled, which leads consequently to rearrangement of materials or equipment on-site (non-value-adding activities). In addition, a high uncertainty of the progress on-site leads fabrication to anticipate production of components and, therefore, to increase inventory at the fabrication shop or on-site. To avoid such inefficiencies in the supply chain, downtimes at the construction site and high inventory levels, the authors propose an approach to synchronizing manufacturing and installation. Aligning manufacturing with the site could first avoid such non-value-adding activities. Furthermore, through JIT and pull-oriented production and delivery, non-value-adding operations (like searching for components on-site) could be reduced and the chances for early detection of quality problems could be improved. In addition, by pulling manufacturing from a site, a higher degree of capacity and resource utilization can be reached.

In traditional ETO CSCs, the economic benefits of a project, reached through scale effects in production, are lost due to an inefficient installation process on-site. One of the major causes of an inefficient installation process on-site is construction interruptions due to a lack of necessary MTO or ETO components. By limiting the amount of WIP throughout the supply chain and by synchronizing the supply chain to the construction site, all dimensions of sustainability can be addressed positively. The proposed long-term control loop limits the number of projects in the system and thus avoids an accumulation of jobs within the production system and an overloading of employees. As a result, the delivery time can be guaranteed to the customer. The short-term control loop avoids a situation where a delay is propagated throughout the supply chain, by measuring in detail the performance of tasks and introducing, in cases of delay, an appropriate capacity flexibility.

The proposed approach shows that the following dimensions of sustainability can be increased in ETO CSCs. From an economic point of view, overall costs for labor, for material and for resources can be reduced and, therefore, ETO companies can increase their competitiveness in the market. From an ecological point of view, the approach reduces unnecessary transportation and express transportation of materials from the job shop to the construction site. Furthermore, a reduction in material handling reduces the consumption of fuel for motorized material handling devices. A reduced need for storage space also has a positive effect on the consumption of energy for production and storage facilities. According to the third aspect in sustainability research, the social aspect, the proposed approach encourages the use of higher qualified personnel at the construction site and/or training of existing staff in organizational logistics and JIT-oriented monitoring and methods. Furthermore, work conditions improve if the work at the construction site is scheduled accurately and if the right material is available in time, avoiding eventually dangerous corrections with inadequate machinery and equipment on-site.

Critically, it must be added that the proposed approach is not applicable to all construction typologies or supply chains. As such, for example, supply chains dealing with bulk materials need other models for production planning and control. A further critical point is the fact that the proposed approach is based on a single industrial case study. Although the company considered is a good and generalizable example of an ETO manufacturer in CSCs, further validations with other companies should be conducted. A further point of criticism and suggestion for further research is the lack of a quantitative assessment tool for the determination of sustainability performance. Such functionality should be integrated into a future IT-supported tool for sustainable production planning and control.

In future research activities, the proposed approach will be extended to coordinate all companies involved in a construction project and the corresponding supply chains. Furthermore, an IT tool to support and apply the proposed approach in industrial practice in different industrial case studies will be developed. Handling the high variability of construction processes and considering a multi-project environment are future challenges in the realization of such an IT tool. 
Acknowledgments: The research presented in this article was started during the project "Modeling and Managing Processes in Construction (MoMaPC)" supported by the Free University of Bozen-Bolzano (Italy) under Grant IN2021 and it was completed within the research project "Collaborative Construction Process Management (Cockpit)" financed by the European Regional Development Fund Investment for Growth and Jobs Programme 2014-2020 under Grant IN2204.

Author Contributions: Patrick Dallasega developed the CONWIP-based approach for synchronization of manufacturing and installation on-site and validated it in the presented case study; Erwin Rauch contributed with expertise in the field of lean methods and production planning and control in manufacturing to synchronize manufacturing and on-site-installation.

Conflicts of Interest: The authors declare no conflict of interest.

\section{References}

1. Carter, C.R.; Liane Easton, P. Sustainable supply chain management: Evolution and future directions. Int. J. Phys. Distrib. Logist. Manag. 2011, 41, 46-62. [CrossRef]

2. Windsperger, A.; Steinlechner, S.; Fischer, M.; Seebacher, U.; Lackner, B.; Hammerl, B.; Kaltenegger, I. Integriertes Nutzungsmodell Zum Effizienteren Rohstoffeinsatz Im Wirtschaftsbereich (Integrated Usage Model for More Efficient Use of Raw Materials in Economics); BMVIT 19/2006; Federal Ministry for Transport, Innovation and Technology: Vienna, Austria, 2006.

3. Browne, J.; Harren, J.; Shivan, J. Production Management Systems. An Integrated Perspective; Addison-Wesley: Harlow, UK, 1996.

4. Schweizer, W. Wertstrom Engineering-Typen-Und Variantenreiche Produktion; Epubli GmbH: Berlin, Germany, 2013; p. 53.

5. Dallasega, P.; Rauch, E.; Matt, D.T. Sustainability in the supply chain through synchronization of demand and supply in ETO-companies. Procedia CIRP 2015, 29, 215-220. [CrossRef]

6. Rauch, E.; Dallasega, P.; Matt, D.T. Synchronization of Engineering, Manufacturing and on-site Installation in Lean ETO-Enterprises. Procedia CIRP 2015, 37, 128-133. [CrossRef]

7. Blismas, N.; Pasquire, C.; Gibb, A. Benefit evaluation for off-site production in construction. Constr. Manag. Econ. 2006, 24, 121-130. [CrossRef]

8. Matt, D.T.; Rauch, E. Implementing Lean in Engineer-to-Order Manufacturing: Experiences from a ETO Manufacturer. In Handbook of Research on Design and Management of Lean Production Systems; Modrák, V., Semančo, P., Eds.; IGI Global: Hershey, PA, USA, 2014; pp. 148-172.

9. Adrodegari, F.; Bacchetti, A.; Pinto, R.; Pirola, F.; Zanardini, M. Engineer-to-order (ETO) production planning and control: An empirical framework for machinery-building companies. Prod. Plan. Control 2015, 26, 910-932. [CrossRef]

10. Nowotarski, P.; Paslawski, J. Barriers in running construction SME-case study on introduction of agile methodology to electrical subcontractor. Procedia Eng. 2015, 122, 47-56. [CrossRef]

11. Singleton, T.; Cormican, K. The influence of technology on the development of partnership relationships in the Irish construction industry. Int. J. Comput. Int. Manuf. 2013, 26, 19-28. [CrossRef]

12. Dong, S.; Feng, C.; Kamat, V.R. Sensitivity analysis of augmented reality-assisted building damage reconnaissance using virtual prototyping. Autom. Constr. 2013, 33, 24-36. [CrossRef]

13. Kim, B.; Kim, C.; Kim, H. Interactive modeler for construction equipment operation using augmented reality. J. Comput. Civ. Eng. 2012, 26, 331-341. [CrossRef]

14. Vrijhoef, R.; Koskela, L. The four roles of supply chain management in construction. Eur. J. Purch. Supply Manag. 2000, 6, 169-178. [CrossRef]

15. Akintoye, A.; McIntosh, G.; Fitzgerald, E. A survey of supply chain collaboration and management in the UK construction industry. Eur. J. Purch. Supply Manag. 2000, 6, 159-168. [CrossRef]

16. Zailani, S.; Jeyaraman, K.; Vengadasan, G.; Premkumar, R. Sustainable supply chain management (SSCM) in Malaysia: A survey. Int. J. Prod. Econ. 2012, 140, 330-340. [CrossRef]

17. Vachon, S.; Mao, Z. Linking supply chain strength to sustainable development: A country-level analysis. J. Clean. Prod. 2008, 16, 1552-1560. [CrossRef]

18. Golicic, S.L.; Smith, C.D. A Meta-Analysis of Environmentally Sustainable Supply Chain Management Practices and Firm Performance. J. Supply Chain Manag. 2013, 49, 78-95. [CrossRef] 
19. Vachon, S.; Klassen, R.D. Extending green practices across the supply chain-The impact of upstream and downstream integration. Int. J. Oper. Prod. Manag. 2006, 26, 795-821. [CrossRef]

20. Yang, L.R. Key practices, manufacturing capability and attainment of manufacturing goals: The perspective of project/engineer-to-order manufacturing. Int. J. Proj. Manag. 2013, 31, 109-125. [CrossRef]

21. Bunz, K.R.; Henze, G.P.; Tiller, D.K. Survey of Sustainable Building Design Practices in North America, Europe, and Asia. J. Archit. Eng. 2006, 12, 33-62. [CrossRef]

22. Shen, L.Y.; Li Hao, J.; Tam, V.W.Y.; Yao, H. A checklist for assessing sustainability performance of construction projects. J. Civ. Eng. Manag. 2007, 13, 273-281.

23. Davies, R.M.; Davies, I.O.E. Barriers to Implementation of Sustainable Construction Techniques. MAYFEB J. Environ. Sci. 2017, 2, 1-9.

24. Ofori, G. Greening the construction supply chain in Singapore. Eur. J. Purch. Supply Manag. 2000, 6, 195-206. [CrossRef]

25. Kofoworola, O.F.; Gheewala, S.H. Estimation of construction waste generation and management in Thailand. Waste Manag. 2009, 29, 731-738. [CrossRef] [PubMed]

26. Shen, L.Y.; Tam, V.W.Y. Implementation of environmental management in the Hong Kong construction industry. Int. J. Proj. Manag. 2002, 20, 535-543. [CrossRef]

27. Oh, S.W.; Chang, H.J.; Kim, Y.S.; Lee, Y.B.; Kim, H.S. An application of PDA and barcode technology for the improvement of information management in construction projects. In Proceedings of the 21st International Symposium on Automation and Robotics in Construction, Jeju Island, Korea, 21 September 2004; pp. 518-524.

28. Chen, Z.; Li, H.; Wong, C.T.C. An application of bar-code system for reducing construction wastes. Autom. Constr. 2002, 11, 521-533. [CrossRef]

29. Cheng, M.Y.; Chen, Y.C. Integrating barcode and GIS for monitoring construction progress. Autom. Constr. 2002, 11, 23-33. [CrossRef]

30. Tzeng, C.T.; Chiang, Y.C.; Chiang, C.M.; Lai, C.M. Combination of radio frequency identification (RFID) and field verification tests of interior decorating materials. Autom. Constr. 2008, 18, 16-23. [CrossRef]

31. Hassan, A.S. Towards Sustainable Housing Construction in Southeast Asia. Agenda 2002, 21, 1-17.

32. Pandit, A.; Zhu, Y. An ontology-based approach to support decision-making for the design of ETO (Engineer-To-Order) products. Autom. Constr. 2007, 16, 759-770. [CrossRef]

33. Ali, A.N.A.; Jainudin, N.A.; Tawie, R.; Jugah, I. Green Initiatives in Kota Kinabalu Construction Industry. Proced. Soc. Behav. Sci. 2016, 224, 626-631. [CrossRef]

34. Raftery, J.; Pasadilla, B.; Chiang, Y.H.; Hui, E.C.; Tang, B.S. Globalization and construction industry development: Implications of recent developments in the construction sector in Asia. Constr. Manag. Econ. 1998, 16, 729-737. [CrossRef]

35. Long, N.D.; Ogunlana, S.; Quang, T.; Lam, K.C. Large construction projects in developing countries: A case study from Vietnam. Int. J. Proj. Manag. 2004, 22, 553-561. [CrossRef]

36. Chritamara, S.; Ogunlana, S.O. Problems experienced on design and build projects in Thailand. J. Constr. Procure. 2001, 7, 73-86.

37. Ohno, T. Toyota Production System: Beyond Large Scale Production; Productivity Press: Cambridge, MA, USA, 1988.

38. Rother, M.; Shook, J. Learning to See-Value Stream Mapping to Create Value and Eliminate Muda; Lean Enterprise Institute: Cambridge, MA, USA, 2009.

39. Bevilacqua, M.; Ciarapica, F.E.; De Sanctis, I. Relationships between Italian companies' operational characteristics and business growth in high and low lean performers. J. Manuf. Technol. Manag. 2017, 28, 250-274. [CrossRef]

40. Ballard, G.; Howell, G. Toward construction JIT. In Lean Construction; Alarco'n, L., Ed.; Taylor \& Francis: New York, NY, USA, 1995; pp. 291-300.

41. Takahashi, K.; Hirotani, D. Comparing CONWIP, synchronized CONWIP, and Kanban in complex supply chains. Int. J. Prod. Econ. 2005, 93-94, 25-40. [CrossRef]

42. Kimura, O.; Terada, H. Design and analysis of pull system: A method of multi-stage production control. Int. J. Prod. Res. 1981, 19, 241-253. [CrossRef]

43. Hopp, W.J.; Spearman, M.L. Factory Physics: Foundations of Manufacturing Management, 2nd ed.; Boston IRWN/McGraw-Hill: Boston, MA, USA, 2001. 
44. Bevilacqua, M.; Ciarapica, F.E.; De Sanctis, I. Lean practices implementation and their relationships with operational responsiveness and company performance: An Italian study. Int. J. Prod. Res. 2017, 55, 769-794. [CrossRef]

45. Papadopoulu, P.C. Application of Lean Scheduling and Production Control in Non-Repetitive Manufacturing Systems Using Intelligent Agent Decision Support. Ph.D. Thesis, The Engineering \& Design Brunel University, London, UK, 2013; p. 7.

46. Spearman, M.L.; Woodruff, D.L.; Hopp, W.J. CONWIP: A pull alternative to KANBAN. Int. J. Prod. Res. 1990, 28, 879-894. [CrossRef]

47. Arbulu, R. Application of Pull and Conwip in Construction Production Systems. In Proceedings of the 14th Annual Conference of the International Group for Lean Construction, Santiago, Chile, 25-27 July 2006; pp. 215-226.

48. Matt, D.T. Adaptation of the value stream mapping approach to the design of lean engineer-to-order production systems. J. Manuf. Technol. Manag. 2014, 25, 334-350. [CrossRef]

49. Anavi-Isakow, S.; Golany, B. Managing multi-project environments through constant work-in-process. Int. J. Proj. Manag. 2003, 21, 9-18. [CrossRef]

50. Carniel-Perrin, B.; Dehe, B.; Bamford, D.; Jolley, K. Pull-logic and ERP within Engineering-to-Order (ETO): The case of a British Manufacturer. In Proceedings of the 5th World Production and Operations Management Conference P\&OM, Havana, Cuba, 6-10 September 2016.

51. Gosling, J.; Towill, D.R.; Naim, M.M.; Dainty, A.R. Principles for the design and operation of engineer-to-order supply chains in the construction sector. Prod. Plan. Control 2015, 26, 203-218. [CrossRef]

52. Forrester, J.W. Industrial Dynamics; Pegasus Communications: Waltham, MA, USA, 1961.

53. Burbidge, J.L. The new approach to production. Prod. Eng. 1961, 40, 769-784. [CrossRef]

54. Woodside, A.G.; Wilson, E.J. Case study research methods for theory building. J. Bus. Ind. Mark. 2003, 18, 493-508. [CrossRef]

55. Gummesson, E. Qualitative research in marketing: Roadmap for a wilderness of complexity and unpredictability. Eur. J. Mark. 2005, 39, 309-327. [CrossRef]

56. Siggelkow, N. Persuasion with case studies. Acad. Manag. J. 2007, 50, 20-24. [CrossRef]

57. Perren, L.; Ram, M. Case-study method in small business and entrepreneurial research. Int. Small Bus. J. 2004, 22, 83-101. [CrossRef]

58. Briscoe, G.; Dainty, A. Construction supply chain integration: An elusive goal? Supply Chain Manag. Int. J. 2005, 10, 319-326. [CrossRef]

59. Matt, D.T.; Dallasega, P.; Rauch, E. Synchronization of the Manufacturing Process and On-Site Installation in ETO Companies. Procedia CIRP 2014, 17, 457-462. [CrossRef]

60. Dallasega, P.; Rauch, E.; Matt, D.T.; Fronk, A. Increasing productivity in ETO construction projects through a lean methodology for demand predictability. In Proceedings of the International Conference on Industrial Engineering and Operations Management (IEOM), Dubai, UAE, 3-5 March 2015; pp. 1-11.

61. Dallasega, P.; Frosolini, E.; Matt, D.T. An approach supporting Real-Time Project Management in Plant Building and the Construction Industry. In Proceedings of the XXI Summer School Francesco Turco, Naples, Italy, 13-15 September 2016.

62. Little, J.D.C. A proof for the Formula: $L=\lambda W$. Oper. Res. 1961, 9, 383-387. [CrossRef]

63. Westkämper, E. Manufuture and sustainable manufacturing. In Manufacturing Systems and Technologies for the New Frontier; Mitsuishi, M., Ueda, K., Kimura, F., Eds.; Springer: London, UK, 2008; pp. 11-14.

64. Rauch, E.; Dallasega, P.; Matt, D.T. Sustainable production in emerging markets through Distributed Manufacturing Systems (DMS). J. Clean. Prod. 2016, 135, 127-138. [CrossRef]

(C) 2017 by the authors. Licensee MDPI, Basel, Switzerland. This article is an open access article distributed under the terms and conditions of the Creative Commons Attribution (CC BY) license (http:/ / creativecommons.org/licenses/by/4.0/). 